\title{
Germline Variations of Apurinic/Apyrimidinic Endonuclease 1 (APEX1) Detected in Female Breast Cancer Patients
}

\author{
Kashif Ali ${ }^{1}$, Ishrat Mahjabeen ${ }^{1}$, Maimoona Sabir ${ }^{1}$, Ruqia Mehmood Baig ${ }^{1,2}$, \\ Maryam Zafeer ${ }^{1}$, Muhammad Faheem ${ }^{3}$, Mahmood Akhtar Kayani ${ }^{1 *}$
}

\begin{abstract}
Apurinic/apyrimidinic endonuclease 1 (APEX1) is a multifunctional protein which plays a central role in the BER pathway. APEX1 gene being highly polymorphic in cancer patients and has been indicated to have a contributive role in Apurinic/apyrimidinic (AP) site accumulation in DNA and consequently an increased risk of cancer development. In this case-control study, all exons of the APEXI gene and its exon/intron boundaries were amplified in 530 breast cancer patients and 395 matched healthy controls and then analyzed by single-stranded conformational polymorphism followed by sequencing. Sequence analysis revealed fourteen heterozygous mutations, seven 5'UTR, one 3'UTR, two intronic and four missense. Among identified mutations one 5'UTR (rs41561214), one 3'UTR (rs17112002) and one missense mutation (Ser129Arg, Mahjabeen et al., 2013) had already been reported while the remaining eleven mutations. Six novel mutations (g.20923366T $>$ G, g.20923435G $>$ A, g.20923462G $>$ A, g.20923516G $>$ A, 20923539G $>$ A, g.20923529C $>$ T) were observed in 5'UTR region, two (g.20923585T $>$ G, g.20923589T $>$ G) in intron1 and three missense (Glu101 Lys, Ala121Pro, Ser123Trp) in exon 4. Frequencues of 5'UTR mutations; g.20923366T $>$ G, g.20923435G $>$ A and 3'UTR (rs17112002) werecalculated as $0.13,0.1$ and 0.1 respectively. Whereas, the frequency of missense mutations Glu101Lys, Ser123Trp and Ser129Arg was calculated as 0.05. A significant association was observed between APEX1 mutations and increased breast cancer by $\sim 9$ fold $(\mathrm{OR}=8.68,95 \% \mathrm{CI}=2.64$ to 28.5$)$ with g.20923435G $>\mathrm{A}(5$ ' UTR $)$ , 13 fold $(\mathrm{OR}=12.6,95 \% \mathrm{CI}=3.01$ to 53.0) with g.20923539G $>\mathrm{A}(5, \mathrm{UTR})$ and $\sim 5$ fold increase with three missense mutations [Glu101 Lys $(O R=4.82,95 \% \mathrm{CI}=1.97$ to 11.80$)$, Ser123Trp $(O R=4.62,95 \% \mathrm{CI}=1.7$ to 12.19), Ser129Arg $(\mathrm{OR}=4.86,95 \% \mathrm{CI}=1.43$ to 16.53) . The incidence of observed mutations was found higher in patients with family history and with early menopause. In conclusion, our study demonstrates a significant association between germ line APEX1 mutations and breast cancer patients in the Pakistani population.
\end{abstract}

Keywords: Germline variations - BER pathway - APEX1 - breast cancer - Pakistan

Asian Pac J Cancer Prev, 15 (18), 7589-7595

\section{Introduction}

DNA damage caused by exogenous carcinogens and endogenous oxygen species is the most important factor for carcinogenesis and genomic instability through activation of oncogenes and inactivation of tumor suppressor genes. Thus, DNA repair play a role in maintaining genomic stability and protecting the cells against carcinogenesis (Zhou et al., 2012).There are several distinct DNA repair pathways including mismatch repair, nucleotide excision repair (NER), base excision repair (BER), homologous recombination repair and nonhomologous end joining repair pathways. BER pathway is the primary guardian against damage that results from cellular metabolism including reactive oxygen species, methylation, deamination and hydroxylation. Genetic variations in BER may result in reduced or defected repair capability and accumulated DNA damage consequently leading to permanent mutations in the genome, which may ultimately contribute to carcinogenesis. Therefore, base excision repair is a universal event in cells for preventing mutagenesis (Zhou et al., 2011; Alanazi et al., 2013; Li et al., 2013; Luo et al., 2014).

Apurinic/apyrimidinic Endonuclease 1 (APEX1) also known as REF-1 is a multifunctional protein which plays a central role in BER pathway. APEX1 initiates DNA repair activity by hydrolyzing the 5'-phosphodiester backbone at the apurinic/apyrimidinic (AP) sites produced by endogenous and exogenous sources thus protecting the cells from accumulation of AP sites in DNA. APE1 can also act as 3'-phosphodiesterase to initiate repair of DNA single strand breaks, which are produced either directly by reactive oxygen species or indirectly through enzymatic removal of damaged bases. In humans, APEX1 is located

${ }^{1}$ Department of Biosciences, COMSATS Institute of Information and Technology, Islamabad, ${ }^{2}$ Department of Zoology, PMAS Arid Agriculture University, Rawalpindi, ${ }^{3}$ Nuclear Medicine, Oncology and Radiotherapy Institute, Chak Shahzad, Islamabad, Pakistan *For correspondence: mkayani@comsats.edu.pk 
on chromosome 14q11.2- q12 and consists of five exons spanning $2.21 \mathrm{~kb}$ (Lo et al., 2009). It has two domains, a DNA-repairing domain and a redox domain. The carboxy-terminus of APEX1 contains the endonuclease activity required for DNA repair and spans residues 61-318, whereas residues 1-127 comprise the redox domain. APEX1 also acts as an important transcriptional coactivator for numerous transcription factors involved in cancer development (Bhakat et al., 2009; Zhang and Wang, 2010) and is considered as a promising tool for anticancer therapy (Zhou et al., 2011).

Variants in different regions of APEX1 gene have been identified and found to influence the susceptibility and progression of different cancers including lung cancer (Lo et al., 2009; Lu et al., 2009), bladder cancer (Wang et al., 2010), glioblastoma (Zhou et al., 2011), cervical cancer (Wang et al., 2013), nasopharyngeal carcinoma (Li et al., 2013) and breast cancer (Zang et al., 2006; Kang et al., 2013). Previously 18 single nucleotide polymorphisms (SNPs) in APEX1 have been identified of which, one functional SNPs in promoter region $(-656$ $\mathrm{T}>\mathrm{G}, \mathrm{rs} 1760944)$ and one in the fifth exon $(1349 \mathrm{~T}>\mathrm{G}$, Glu148Asp, rs1130409) have been widely investigated (Zhou et al., 2011: Li et al., 2013). Asp148Glu variant resides in the carboxy-terminus with no direct impact on endonuclease or DNA-binding activities. However, variants outside the DNA repair domain of APEX1, such as residues 61-318 or promoter region could be markers for the pathogenic SNP and may be informative (Avery, 2007; Lo et al., 2009; Lu et al., 2009). APEX1 polymorphic system and cancer susceptibility have been investigated in limited number of populations like Caucasian, Asian and African. In this study, we have comprehensively screened APEX1 for mutations and then these mutations were further analyzed for their possible association with breast cancer risk in female patients of Pakistani origin.

\section{Materials and Methods}

\section{Collection of samples}

Present study was conducted with a prior approval from ethical committees of both COMSATS Institute of Information Technology Islamabad (CIIT) and collaborating hospitals. A total of 530 female patients with histologically confirmed breast cancer were recruited from Nuclear Medicine, Oncology and Radiotherapy Institute (NORI) Islamabad Pakistan. Additionally 395 age and ethnicity matched cancer free healthy female individuals were also recruited as controls. The inclusion criterion for the controls was absence of prior history of cancer or pre-cancerous lesions. Patients and controls suffering from any other familial disease (diabetes, blood pressure and cardiovascular impairment) were excluded from this study. After obtaining informed consent, all individuals were personally interviewed using the specifically designed questionnaire. Information about age, age at menarche, menopausal status, menopausal age, family history, ethnic group was collected from both patients and control individuals. Detailed histopthalogical reports of patients were also recorded for their clinical characterization.
DNA extraction and polymerase chain reaction $(P C R)$

DNA was extracted from white blood cells, using standard phenol-chloroform extraction method (Masood et al., 2011) with minor alterations. Freshly extracted DNA was quantified by spectrophotometry and yield gel electrophoresis and stored at $-20^{\circ} \mathrm{C}$ till further processing. Human APEX1 exon sequence was taken from Ensemble. Primers were designed using primer 3 software and checked for specific amplification using BLAST. Whole coding region including exon intron boundaries of approximately $60 \mathrm{bp}$ sequence of APEX1 was investigated-identify novel and any splice site variation in addition-previously reported mutations. Each PCR reaction was performed in a $10 \mu$ reaction mixture containing $1 \mu \mathrm{l}$ of genomic DNA (approximately $50 \mathrm{ng}$ ) templates, $1 \mu \mathrm{l}(10 \mathrm{mM})$ of each primer, $1 \mu \mathrm{l}$ nuclease free water and $5 \mu \mathrm{l} \mathrm{PCR}$ master mix (Thermo Scientific) containing $0.05 \mathrm{U} / \mu \mathrm{lTaq}$ DNA polymerase, reaction buffer, $4 \mathrm{mM} \mathrm{MgCl} 2,0.4 \mathrm{mM}$ of each dNTP. PCR conditions were initial melting step at $94^{\circ} \mathrm{C}$ for $5 \mathrm{~min}, 35$ cycles each comprised of $94^{\circ} \mathrm{C}$ for $45 \mathrm{sec}$, exon specific annealing temperature for $1 \mathrm{~min}$ and $72^{\circ} \mathrm{C}$ for $1 \mathrm{~min}$. It was followed by a final extension step at $72^{\circ} \mathrm{C}$ for $10 \mathrm{~min}$ and finally held at $4^{\circ} \mathrm{C} .2 \mu \mathrm{l}$ of PCR products along with loading dye were electrophoresed on a $2 \%$ agarose gel and stained with ethidium bromide. 100bp ladder was also loaded as standard for quantification of amount and confirmation of PCR product size.

\section{Mutational screening and sequence analysis}

Single stranded conformational polymorphism (SSCP) assay was used for mutational analysis of PCR products. Samples with altered electrophoretic mobility were reamplified in a separate reaction and were analysed by direct sequencing-confirm and characterize the nature of mutations/ polymorphisms. Control (normal) samples were also sequenced along with cancerous samplescompare the sequencing results. Sequencing was carried out by MC lab (USA). Results after DNA sequencing were analysed using BioEdit (version 7.0.5) software.

\section{Data analysis}

$\chi^{2}$-test and Fisher exact test were used-evaluate the differences in selected demographic variables, family history, tumor types, tumor grades, ER/ PR and HER2/nue status by using the Graph Pad Prism 5 Demo. Spearman correlation coefficient was used-assess the correlations among the observed mutations and clinical and histo-pathological parameters. Missense mutations were also analysed in-silico via Alamut biosoftware (version 2.2)-predict the pathogenicity of point mutations, PhyloP for conservation level of mutated nucleotides and amino acids along with Grantham distance for physicochemical changes in amino acid structure.

\section{Results}

Mean age of breast cancer patients and controls was calculated as $46.4( \pm 11.59)$ and $42.80( \pm 12.96)$ years respectively. Patients and control individuals with age 
$>40$ years were significantly $(\mathrm{p}<0.007)$ more afflicted in number than patients of $\leq 40$ years age.

In the present study, all exons of APEX1 were screened extensively for germline mutations involving SSCP followed by sequence analysis in 530 patients and 395 control individuals. Fourteen different types of mutations were observed, which include seven 5'UTR, one 3'UTR, two Intronic and four missense mutations. All mutations observed in this study were heterozygous. Among identified mutations one 5'UTR (g.20923416C>T, rs41561214), one
3'UTR (20925669A>T, rs 17112002) and one missense mutation (Ser129Arg, Mahjabeen et al., 2013) has already been reported while remaining elven mutations are novel. Six novel mutations (g.20923366T $>$ G, g.20923435G $>$ A, g.20923462G >A, g.20923516G >A, 20923539G >A, g.20923529C $>$ T) were observed in 5'UTR region, two (g.20923585T $>$ G, g.20923589T $>$ G) in intron 1 and three (g.20924881G>A, Glu101Lys; g.20924941G>C, Ala121Pro; g.20924948C>G, Ser123Trp) were observed in exon 4 (Figure 1).

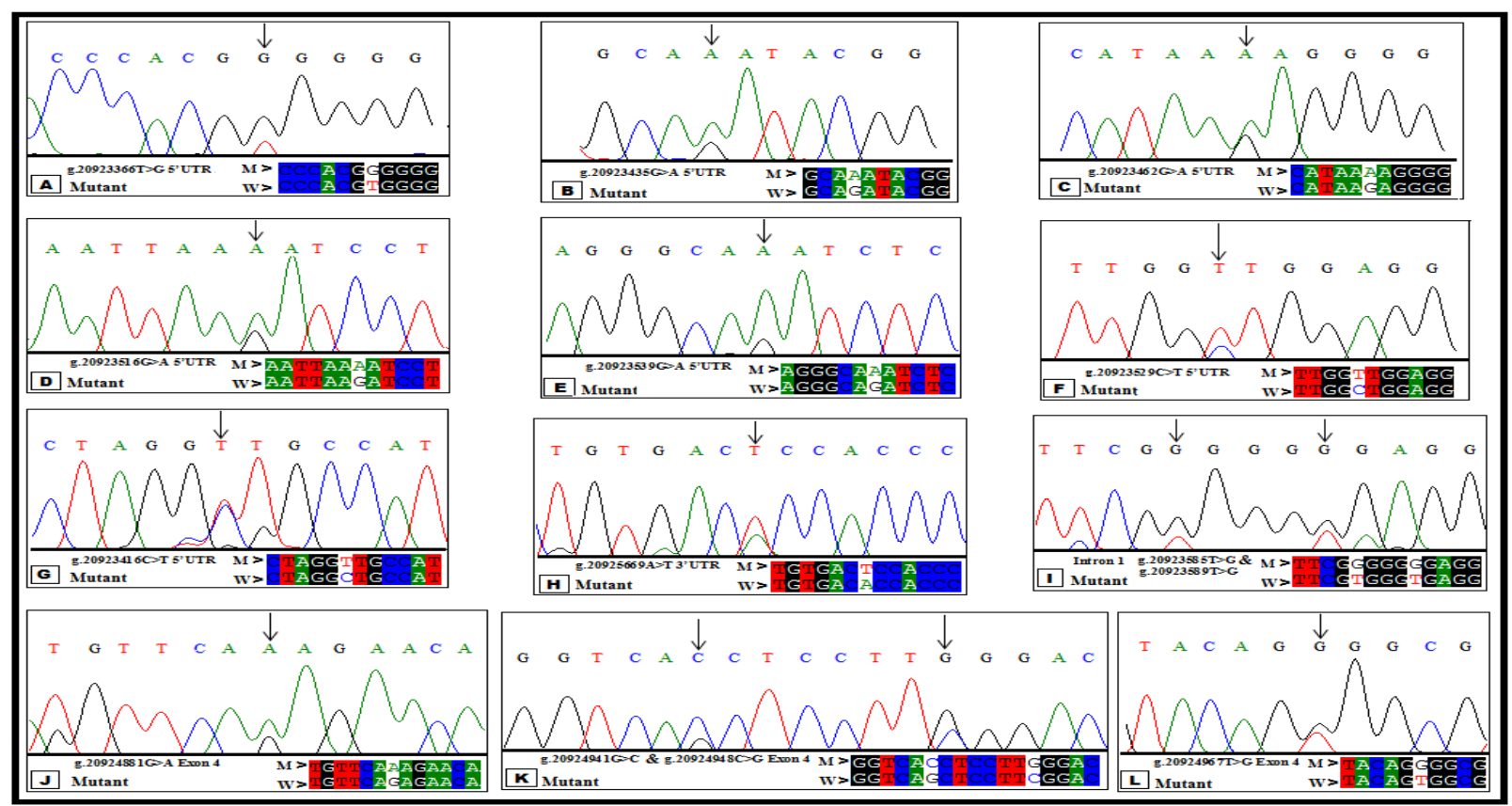

Figure 1. Sequencing electropherogram of polymorphisms of APEX1.A, B, C, D, E, F \& G are substitutions in 5`UTR region \{(A) g.20923366 T>G substitution in 5’UTR region. (B) g.20923435 G>A substitution in 5’UTR region. (C) g.20923462 G > A substitution in 5`UTR region. (D) g.20923516 G>A substitution in 5’UTR region. (E) g.20923539 G>A substitution in 5`UTR region. (F) g.20923529 C>T substitution in 5’UTR region. (G) g.20923416 C>T (rs41561214) substitution in 5’UTR region.\} (H) g.20925669 A>T (rs 17112002) substitution in 3'UTR region. (I) g.20923585 T>G \& g.20923589 T>G substitutions in intronic region. J, K \& $\mathbf{L}$ are Missense substitutions in Exon 4 \{(J) Missense mutation Glu101Lys showing g.20924881G>A substitution resulting in change of codon from GAG to AAG encoding the amino acid Glutamic acid instead of Lysine. (K) Missense mutation Ala121Pro showing g.20924941G $>$ C substitution resulting in change codon from GCT to CCT encoding the amino acid Proline instead of Alanine and Missense mutation Ser123Trp showing g.20924948 C>G substitution resulting in change of codon from TCG to TGG encoding the amino acid Serine instead of Tryptophan. (L) g.20924967 T>G substitutions resulting in change of codon from AGT to AGG encoding the amino acid Serine instead of Arginine (Ser129Arg).\}

Table 1. Mutations and their Allele Frequencies Observed in the APEX1 Gene in Breast Cancer Patients

\begin{tabular}{|c|c|c|c|c|c|c|}
\hline \multirow[t]{2}{*}{ Mutation/ Exon Chr14(GRCh37) } & \multicolumn{2}{|r|}{ Patients } & \multicolumn{2}{|r|}{ Control } & \multirow[t]{2}{*}{ Odd Ratio (95\% Ci) } & \multirow[t]{2}{*}{$\mathrm{p}$ value } \\
\hline & $\overline{\text { No. }}$ & $\begin{array}{l}\text { Allele frequency } \\
\text { Minor/ Major }\end{array}$ & No. & $\begin{array}{l}\text { Allele frequency } \\
\text { Minor/ Major }\end{array}$ & & \\
\hline g.20923366T>G 5'UTR & 46 & G $0.13 / \mathrm{T} 0.87$ & 9 & G $0.35 / \mathrm{T} 0.65$ & $4.0762(1.9706-8.4315)$ & $<0.0001$ \\
\hline g.20923435G >A 5'UTR & 33 & A $0.1 / \mathrm{G} 0.9$ & 3 & A $0.12 / \mathrm{G} 0.88$ & $8.6761(2.6413-28.4996)$ & $<0.0001$ \\
\hline g.20923462G>A 5'UTR & 29 & A $0.08 / \mathrm{G} 0.92$ & 4 & A $0.15 / \mathrm{G} 0.85$ & $5.6582(1.9726-16.2297)$ & $<0.0002$ \\
\hline g.20923516G >A 5'UTR & 25 & A $0.07 / \mathrm{G} 0.93$ & 5 & A $0.19 / \mathrm{G} 0.81$ & $3.8614(1.4649-10.1785)$ & $<0.004$ \\
\hline g.20923539G >A 5'UTR & 32 & A $0.09 / \mathrm{G} 0.91$ & 2 & A $0.09 / \mathrm{G} 0.91$ & $12.6265(3.0075-53.0105)$ & $<0.0001$ \\
\hline g.20923529C $>$ T 5'UTR & 12 & Т $0.03 / \mathrm{C} 0.97$ & 0 & $\mathrm{~T} 1.0 / \mathrm{C} 00$ & $4.2619(1.4099-12.883)$ & $<0.009$ \\
\hline g.20923416C > T 5'UTR (rs41561214) & 24 & Т $0.07 / \mathrm{C} 0.93$ & 0 & $\mathrm{~T} 1.0 / \mathrm{C} 00$ & $5.0733(2.2728-11.3245)$ & $<0.0001$ \\
\hline g.20925669A > T 3'UTR (rs17112002) & 34 & Т $0.1 / \mathrm{A} 0.9$ & 0 & $\mathrm{~T} 1.0 / \mathrm{A} 00$ & $5.4234(2.7409-10.7313)$ & $<0.0001$ \\
\hline g.20923585T>G Intron 1 & 25 & G $0.07 / \mathrm{T} 0.93$ & 0 & G 1.0/T 00 & $5.1154(2.3266-11.2467)$ & $<0.0001$ \\
\hline g.20923589T>G Intron 1 & 27 & G $0.08 / \mathrm{T} 0.92$ & 0 & G $1.0 / \mathrm{T} 00$ & $5.1938(2.4289-11.1058)$ & $<0.0001$ \\
\hline g.20924881G>A Exon 4 Glu101Lys & 19 & A $0.05 / \mathrm{G} 0.95$ & 0 & A $1.0 / \mathrm{G} 00$ & $4.8224(1.9699-11.8054)$ & $<0.0003$ \\
\hline g.20924941G $>$ C Exon 4 Ala121Pro (rs371585266G $>$ T) & 8 & $\mathrm{C} 0.02 / \mathrm{G} 0.98$ & 0 & C $1.0 / \mathrm{G} 00$ & $3.6783(0.9762-13.86)$ & 0.08 \\
\hline g.20924948C>G Exon 4 Ser123Trp & 16 & G $0.05 / \mathrm{C} 0.95$ & 0 & G $1.0 / \mathrm{C} 00$ & $4.6246(1.754-12.1928)$ & $<0.001$ \\
\hline g.20924967T>G Exon 4 Ser129Arg & 19 & G $0.05 / \mathrm{T} 0.95$ & 3 & G $0.12 / \mathrm{T} 0.88$ & $4.8584(1.4275-16.5349)$ & $<0.004$ \\
\hline
\end{tabular}

*OR: odds ratio; CI: confidence interval; aORs for logistic regression analysis; bp $>0.05$; by $\mathrm{X}^{2}$-test for trend 
Increased breast cancer risk was found associated with different mutations when compared with controls (Table 1). In case of 5'UTR mutations, 4-fold increase in breast cancer risk was associated with $\mathrm{g}$.20923366T $>\mathrm{G}$ $(\mathrm{OR}=4.08,95 \% \mathrm{CI}=1.97-8.43), \mathrm{g} .20923516 \mathrm{G}>\mathrm{A}$ $(\mathrm{OR}=3.86,95 \% \mathrm{CI}=1.46-10.18), \mathrm{g} .20923529 \mathrm{C}>\mathrm{T}$ ( $\mathrm{OR}=4.26,95 \% \mathrm{CI}=1.41-12.88)$ mutations, whereas $\sim 5$ fold increased breast cancer risk was associated with g. $20923416 \mathrm{C}>\mathrm{T}(\mathrm{OR}=5.07,95 \% \mathrm{CI}=2.27-11.32), \sim 6$ fold increase with $\mathrm{g} .20923462 \mathrm{G}>\mathrm{A}(\mathrm{OR}=5.66,95 \% \mathrm{CI}=1.97$ $16.23), \sim 9$ fold increase with $\mathrm{g} .20923435 \mathrm{G}>\mathrm{A}(\mathrm{OR}=8.68$, $95 \% \mathrm{CI}=2.64-28.50)$ and $\sim 13$ fold increase with g.20923539G $>$ A $(\mathrm{OR}=12.63,95 \% \mathrm{CI}=3.01-53.01)$ mutations. In similar fashion $\sim 5$ fold increase in breast cancer risk was observed in 3'UTR mutations g.20925669A $>\mathrm{T}(\mathrm{OR}=5.42,95 \% \mathrm{CI}=2.74-10.73)$ and both intronic mutations g.20923585T $>\mathrm{G}(\mathrm{OR}=5.11,95 \%$ $\mathrm{CI}=2.32-11.25)$ and $\mathrm{g} .20923589 \mathrm{~T}>\mathrm{G}(\mathrm{OR}=5.19,95 \%$ $\mathrm{CI}=2.43-11.10$ ). While analyzing missense mutations, a significantly increased breast cancer risk was also found associated with missense mutations when compared with controls showing $\sim 5$ fold increase with three mutations \{Glu101Lys $(\mathrm{OR}=4.82,95 \% \mathrm{CI}=1.97-11.80)$, Ser123Trp $(\mathrm{OR}=4.62,95 \% \mathrm{CI}=1.7-12.19)$, Ser129Arg $(\mathrm{OR}=4.86$, $95 \% \mathrm{CI}=1.43-16.53)\}$ and $\sim$ fold increase with Ala121Pro
$(\mathrm{OR}=3.68,95 \% \mathrm{CI}=0.98-13.86)$.

Missense mutations were also analysed via Alamut biosoftware-check the conservation levels of mutated nucleotides and amino acids along with in-silico predictions about Align GVGD score, Grantham distance; SIFT score, Mutation Taster (Table 2). Mutation taster predicted three missense mutations (Glu101Lys, Ser123Trp, Ser129Arg) as potentially disease causing (p-1.0). Greater physiochemical difference was predicted between Serine and Tryptophan amino acids (Ser123Trp; Grantham distance=177) and Serine and Arginine amino acids (Ser129Arg; Grantham distance=110).

Association of mutations observed in this study were also correlated with different clinico-pathological parameters including family history, menopausal age, HER-2/nue and ER/PR status. Frequency of patients with family history was observed significantly higher $(p<0.0001)$ compared-frequency of control individuals. As presented in Table 4, significantly higher frequency of 3'UTR mutation, g.20925669A > T (p<0.009) and two missense mutations Glu101Lys $(\mathrm{p}<0.009)$ and Ser129Arg $(\mathrm{p}<0.05)$ was observed in patients with family history when compared with controls. Correlations between frequency of APEX1 mutations and menopausal age of breast cancer patients (Table 4) showed that the frequency

Table 2. Mutations in APEX1 Gene in Breast Cancer Patients with Conservation Score, SIFT Score, Align GVGD Score, Grantham Distance and Mutation Taster Prediction

\begin{tabular}{|c|c|c|c|c|c|}
\hline $\begin{array}{l}\text { Change in Nucleotide with its conservation } \\
\text { level PhyloP score } \\
{[-14.1 ; 6.4]}\end{array}$ & $\begin{array}{l}\text { Amino acid change with } \\
\text { its conservation level } \\
\text { (considering } 13 \text { species) }\end{array}$ & $\begin{array}{l}\text { SIFT score } \\
\text { (median) }\end{array}$ & $\begin{array}{l}\text { Align GVGD score } \\
\qquad(\mathrm{C} 0-\mathrm{C} 65)\end{array}$ & $\begin{array}{l}\text { Grantham } \\
\text { dist. } \\
(0-215)\end{array}$ & $\begin{array}{l}\text { Mutation } \\
\text { Taster } \\
\text { (p- value) }\end{array}$ \\
\hline $\begin{array}{l}\text { g.20924881G }>\text { A } \\
\text { Highly conserved nucleotide phyloP: } 4.32 \text { Highly } \\
\text { g. } 20924941 \mathrm{G}>\mathrm{C} \\
\text { Weakly conserved nucleotide phyloP: } 1.66 \\
\text { g.20924948C }>\text { G } \\
\text { Moderately conserved nucleotide phyloP: } 2.55 \\
\text { g.20924967T }>\text { G }\end{array}$ & $\begin{array}{l}\text { Glu101Lys } \\
\text { conserved amino acid, up to Baker's yeast } \\
\text { Ala121Pro } \\
\text { Moderately conserved amino acid } \\
\text { Ser123Trp } \\
\text { Moderately conserved amino acid } \\
\text { Ser129Arg }\end{array}$ & $\begin{array}{l}\text { Tolerated } 0.18 \\
\quad-2.95 \\
\text { Tolerated } 0.22 \\
\quad-2.95 \\
\text { Deleterious } 0.01 \\
\quad-2.95 \\
\text { Tolerated } 0.16\end{array}$ & $\begin{array}{l}\text { C0 (GV: 95.14-GD: 0.00) } \\
\text { C0 (GV: 227.66-GD: 0.00) } \\
\text { C15 (GV: 120.14-GD: 97.50) } \\
\text { C0 (GV: 141.06-GD: 0.00) }\end{array}$ & $\begin{array}{r}27 \\
177 \\
110\end{array}$ & $\begin{array}{l}\begin{array}{c}\text { Disease causing } \\
(\mathrm{p}-1.0) \\
\text { Polymorphism } \\
(\mathrm{p}-1.0)\end{array} \\
\text { Disease causing } \\
\quad(\mathrm{p}-1.0) \\
\text { Disease causing }\end{array}$ \\
\hline Weakly conserved nucleotide phyloP: 0.12 & Moderately conserved amino acid & -2.95 & & & $(\mathrm{p}-1.0)$ \\
\hline
\end{tabular}

Table 3. Correlation between APEX1 Mutations and Tumor Types, ER/PR Status and HER-2/neu Status in Breast Cancer Patients

\begin{tabular}{|c|c|c|c|c|c|c|c|c|c|}
\hline \multirow[t]{2}{*}{ Mutations } & \multicolumn{3}{|c|}{ Type of Tumor } & \multicolumn{2}{|c|}{ ER Status } & \multicolumn{2}{|c|}{ PR Status } & \multicolumn{2}{|c|}{ HER-2/neu Status } \\
\hline & $\begin{array}{c}\text { DCIS } \\
\text { No }(\%)\end{array}$ & $\begin{array}{c}\text { IDC } \\
\text { No }(\%)\end{array}$ & $\begin{array}{c}\text { ILC } \\
\text { No }(\%)\end{array}$ & $\begin{array}{c}\text {-ve } \\
\text { No }(\%)\end{array}$ & $\begin{array}{c}+\mathrm{ve} \\
\text { No }(\%)\end{array}$ & $\begin{array}{c}\text {-ve } \\
\text { No }(\%)\end{array}$ & $\begin{array}{c}\text { +ve } \\
\text { No }(\%)\end{array}$ & $\begin{array}{c}\text {-ve } \\
\text { No }(\%)\end{array}$ & $\begin{array}{c}\text { +ve } \\
\text { No }(\%)\end{array}$ \\
\hline g.20923366T>G 5'UTR & $8(10.25)$ & $32(14.81)$ & $4(10.25)$ & $29(13.87)$ & $13(11.50)$ & $28(13.66)$ & $14(11.57)$ & $24(14.46)$ & $16(13.22)$ \\
\hline g.20923435G>A 5'UTR & $7 \quad(8.97)$ & $24(11.11)$ & $2(5.13)$ & $19(9.09)$ & $13(11.50)$ & $16(7.8)$ & $16(13.22)$ & $16(9.76)$ & $12(9.91)$ \\
\hline g.20923462G >A 5'UTR & $8(10.25)$ & $16(7.4)$ & $5(12.82)$ & $16(76.55)$ & $12(10.62)$ & $16(7.8)$ & $12(9.91)$ & $15(9.14)$ & 11 (9.09) \\
\hline g.20923516G >A 5'UTR & $4(5.13)$ & $17(7.87)$ & $2(5.13)$ & $18 \quad(8.61)$ & $6 \quad(5.30)$ & $18(8.78)$ & $6 \quad(4.96)$ & $17(10.36)$ & $6 \quad(4.96)$ \\
\hline g.20923539G >A 5'UTR & $9(11.54)$ & $21(9.72)$ & $2(5.13)$ & $20 \quad(9.57)$ & $10(10.62)$ & $21(10.24)$ & $9 \quad(7.44)$ & $16(9.76)$ & 12 (9.91) \\
\hline g.20923529C > T 5'UTR & $5(6.41)$ & $6 \quad(2.77)$ & $1(2.56)$ & $6 \quad(2.87)$ & $4(3.35)$ & $8 \quad(3.9)$ & $2(1.65)$ & $5(3.04)$ & $4 \quad(3.3)$ \\
\hline g.20923416C>T5'UTR (rs41561214) & $6 \quad(7.69)$ & $11(5.09)$ & $6(15.38)$ & $15(7.18)$ & $8 \quad(7.08)$ & $14(6.83)$ & $9 \quad(7.44)$ & $8(4.87)$ & $9 \quad(7.44)$ \\
\hline g.20925669A > T 3'UTR (rs17112002) & $8(10.25)$ & $23(10.65)$ & $2(5.13)$ & $19(9.09)$ & $13(11.50)$ & $19(9.27)$ & $13(10.74)$ & $12(7.32)$ & $13(10.74)$ \\
\hline g.20923585T>G Intron 1 & $6(7.69)$ & $14(6.48)$ & $3(7.69)$ & $17 \quad(8.13)$ & $5(4.42)$ & $14(6.82)$ & $8(6.61)$ & $13(7.93)$ & $7(5.78)$ \\
\hline g.20923589T>G Intron 1 & $6 \quad(7.69)$ & $15(6.94)$ & $3(7.69)$ & $16(76.55)$ & $9 \quad(7.96)$ & $16(7.8)$ & $13(10.74)$ & $15(9.14)$ & $8 \quad(6.61)$ \\
\hline g.20924881G>A Exon 4 p.Glu101Lys & $2(2.56)$ & $14(6.48)$ & $1(2.56)$ & $10 \quad(4.78)$ & $7 \quad(6.19)$ & $11(5.36)$ & $6(4.96)$ & $7 \quad(4.27)$ & $6 \quad(4.96)$ \\
\hline g.20924941G>C Exon 4 p.Ala121Pro & $2(2.56)$ & $5(2.31)$ & $1(2.56)$ & $5 \quad(2.39)$ & $2(2.21)$ & $5(2.43)$ & $2(1.65)$ & $3(1.83)$ & $4(3.3)$ \\
\hline g.20924948C > G Exon 4 p.Ser123Trp & $4 \quad(5.13)$ & $10(4.63)$ & $2(5.13)$ & $10 \quad(4.78)$ & $3(2.65)$ & $10(4.87)$ & $3(2.48)$ & $7 \quad(4.27)$ & $6 \quad(4.96)$ \\
\hline g.20924967T>G Exon 4 p.Ser129Arg & $3(3.85)$ & $8(3.70)$ & $5(12.82)$ & $9(4.30)$ & $8 \quad(7.08)$ & $9(4.39)$ & $8 \quad(6.61)$ & $6 \quad(3.66)$ & $7 \quad(5.78)$ \\
\hline Correlationa & \multicolumn{3}{|c|}{$0.710 * *$} & \multicolumn{2}{|c|}{$0.756 * *$} & \multicolumn{2}{|c|}{$0.720 * *$} & \multicolumn{2}{|c|}{$0.782 * *$} \\
\hline p-value ${ }^{b}$ & \multicolumn{2}{|l|}{0.004} & & \multicolumn{2}{|l|}{0.002} & \multicolumn{2}{|l|}{0.004} & \multicolumn{2}{|l|}{0.001} \\
\hline
\end{tabular}

aPearson correlation coefficient; ${ }^{\mathrm{b}} \mathrm{p}$ value for $\chi^{2}$ test; $\mathrm{p}<0.05$ is considered statistically significant ; IDC: invasive ductal carcinoma; DCI: Ductal Carcinoma in Situ; LCI: Lobular Carcinoma in Situ; ER: Estrogen Receptor; PR: Progesterone Receptor; HER-2/nue: Human Epidermal Growth Factor Receptor 2 
of 5'UTR and intronic mutations were significantly higher in patients with early menopause (menopause $\leq 50$ years) when compared-controls and late menopausal patients. Majority of the breast cancer patients were histopathologically of invasive ductal carcinoma (64.86\%), grade-II (40.00\%), ER -ve (64.9\%), PR -ve (62.88\%) and HER-2/nue -ve (57.54\%). Frequency of APEX1 mutations was also observed significantly higher in patients with Invasive ductal carcinoma, negative PR status $(\mathrm{p}<0.004)$, negative ER $(\mathrm{p}<0.002)$ and negative HER-2/neu Status $(\mathrm{p}<0.001)$. All observed APEX1 mutations were found significantly correlated with tumor types $\left(\mathrm{r}=0.710^{* *}, \mathrm{p}<0.004\right)$ ER status $\left(\mathrm{r}=0.756^{* *}, \mathrm{p}<0.002\right)$ $\mathrm{PR}$ status $\left(\mathrm{r}=0.720^{* *}, \mathrm{p}<0.004\right)$ and HER-2/neu Status $(\mathrm{r}=0.782 * *$, $\mathrm{p}<0.001$ ) of breast cancer patients (Table 3 ).

\section{Discussion}

AImpaired base-excision repair (BER) function can give rise-the accumulation of DNA damage and initiation of cancer. Epidemiologic studies have linked single nucleotide polymorphisms (SNPs) in BER pathway genes-increased human cancer risk including breast cancer which have been evaluated in different populations in past by focusing on three key genes: $\mathrm{X}$-ray repair cross-complementing protein 1 (XRCC1), 8-oxoguanine DNA glycosylase (OGG1) and apurinic/apyrimidinic endonuclease 1(APEX1) (Hu et al., 2001; Zhang et al., 2006; Lo et al., 2009; Lu et al., 2009; Li et al., 2011; Karahalil et al., 2012; Mahjabeen et al., 2013; Kim et al., 2013; Popanda et al., 2013 ). APEX1 is multifunctional protein playing an important role in DNA repair process through AP-endonucleolytic 3' phosphodiesterase, 3'-5' exonuclease and 3' phosphatase activities. APEX1 is also involved in numerous critical cellular responses including tumor occurrence and development, oxidative stress, cell cycle regulation and apoptosis (Zhang and Wang, 2010). It is the only known repair enzyme with self-regulation system (Dyrkheeva et al., 2007). Objective of this study was mutational screening of APEX1 gene and its association with other clinico- histopathological parameters in breast cancer patients.

In this study all exons of APEX1 gene was screened for genomic variation in 530 breast cancer cases and 395 controls individuals. A total of fourteen mutations were identified in patients and in some control individuals. This includes seven mutations in 5'UTR region, one in 3'UTR region, two intronic and four missense mutations. Out of these observed mutations 11 were novel and three already reported mutations (rs41561214, rs17112002 and Ser129Arg by Mahjabeen et al., 2013). Most of the mutations in 5'UTR, 3'UTR and intronic region were significantly higher in breast cancer patients compared-healthy control individuals. Promoter region and 5' UTR is important for the regulation of translation of transcript (Lodish and Havery, 2004). Polymorphisms in promoter region can influence interactions between transcriptional factors and their ability-recognize DNA sequences in a promoter region and thus affect gene expression (Luo et al., 2014) so mutations in these regions might be very crucial for cellular functioning. Avery (2007) suggested that variants outside the DNA repair domain such as 5'UTR or promoter regions of APEX1 are informative and may be markers for the disease-causing single nucleotide polymorphisms (SNPs). Various SNPs have been reported in 5'UTR, 3'UTR and promoter regions of APEX1 gene and foundinfluence the susceptibility and progression of lung cancer (Lo et al., 2009; Lu et al., 2009), bladder cancer (Wang et al., 2010), glioblastoma (Zhou et al., 2011), breast cancer (Kang et al., 2013; 


\section{Kashif Ali et al}

Luo et al., 2014) and cervical cancer (Wang et al., 2013) risk in Asian populations.

In addition to these mutations we observed four missense mutations (Glu101Lys, Ala121Pro, Ser123Trp, Ser129Arg) in exon 4 which cover both the redox domain and DNA-repairing domain of APEX1. Glu101Lys at residue 101 is in the redox domain while, Ala121Pro, Ser123Trp, Ser129Arg are found in DNA-repairing domain of APEX1. APEX1 protein has a spatial configuration and mainly constituted by two overlapping functional domains at $\mathrm{N}$ and Cterminals. The Nterminal domain is considered-be responsible for the redox function and modify the DNAbinding capacity of multiple transcriptional factors and is involved in regulating gene expression (Wong et al., 2003; Dyrkheeva et al., 2007; Zhang and Wang, 2010). C-terminal domain performs DNA repair functions and protects cells from the cytotoxicity caused by the continuously accumulating exogenous and endogenous AP site mutation (Zhang and Wang, 2010). Structural prediction of Ser129Arg variant in APEX1 by Mahjabeen et al. (2013), has shown no major change in protein structure compared with wildtype protein but APEX1-compromised cells are more susceptible to oxidative stress mainly due to reduced redox and 3'phosphodiestrase activity impacting cell survival, pushing it towards apoptosis (Fishel et al., 2007). Presence of identified missense mutations in both Redox and Repair domains signify that how repair process of DNA might be affected due to inhibition of Redox and repair activity of APEX protein. Missense mutations observed in this study were also analysed via Alamut biosoftware to check the conservation level of mutated nucleotides and encoded amino acids. It was predicted that observed missense mutations especially of highly conserved nucleotides and amino acids have shown some deleterious, potentially disease causing effects resulting physiochemical alterations in structure of amino acids. In-silico predictions about mutations using PolyPhen-2 (Adzhubei et al., 2010), SIFT (Kumar et al., 2009) and Mutation Taster (Schwarz et al., 2010) softwares have previously been considered an important tool in exploration of possible effects of mutations.

APEX1 mutations observed in this study were significantly correlated with different clinico-pathological parameters. Mutation frequency was found higher in patients with invasive ductal carcinoma, tumors grade II, family history of cancer, early menopause and negative ER, PR, HER-2/neu status which have been previously reported-contribute in breast cancer development in Pakistani populations (Naeem et al., 2008; Azizun-Nisa et al., 2008; Sharif et al., 2010; Ahmed et al., 2011) and worldwide (Dumitrescu et al., 2005; Ahmed et al., 2011; Popanda et al., 2013). Woman's breast cancer risk is two or more times greater if she has a family history of cancer (Ahmed et al., 2011). Estrogen and progesterone receptors (ER, PR) and HER-2/neu greatly influence the management of the malignancy (Rampaul et al., 2001) and generally has been found-be lower in Asian countries than those in the Africa, western world, USA and Australia (Ahmed et al., 2007; Hedayati-Moghadam 2008; Ahmed et al., 2011). Relation of menopausal age with breast cancer has been reported inconsistently (Schultz et al., 2005; Shakeel et al., 2013) where we cannot ignore the effects of adjuvant treatment of breast cancer on their menopausal age (Rosenberg and Partridge, 2013).

In conclusion, our study demonstrates a significant association of germ line APEX1 mutations with breast cancer in Pakistani population. The data suggests that a combination of 5'UTR mutations and missense mutations, or any other mutation linked-it in the same gene or gene in vicinity, could conceivably play a role in the process of breast carcinogenesis in Pakistani population. Moreover in line with previous findings, inhibition of DNA repair or redox or both activities of APEX1 due to mutations or any inhibitor could potentially sensitize the tumour cells to therapeutic agents, making APEX1 an attractive molecular target in the treatment of cancer. These molecular and epidemiological findings provide evidence that APEX1, a DNA repairing gene could prove to be a good candidate of better diagnosis, treatment and prevention of breast cancer but more detailed studies are needed for a clearer picture of APEX1 gene and protein in pathogenesis of breast cancer.

\section{Acknowledgements}

All authors wish to acknowledge the patients and control individuals who contributed-this research work. We are also thankful-hospital staff (Nuclear Medicine, Oncology and Radiotherapy Institute Islamabad (NORI) Pakistan, for their help and cooperation. This study was supported by a grant from Higher Education Commission, Islamabad (Pakistan).

\section{References}

Adzhubei IA, Schmidt S, Peshkin L, et al (2010). A method and server for predicting damaging missense mutations. Nat Methods, 7, 248-9.

Ahmed HG, Al-Adhraei MA, Al-Thobhani AK (2011). Correlations of hormone receptors (ER and PR), Her2/ neu and p53 expression in breast ductal carcinoma among Yemeni women. Open Cancer Immunol J, 4, 1-9.

Ahmed HG, Safi SH, Shumo AI, Abdulrazig M (2007). Expression of estrogen and progesterone receptors among Sudanese women with breast cancer: immunohistochemical study. Sudan J Medical Stud, 2, 5-6.

Alanazi M, Pathan AA, Shaik JP, Amri AA, Parine NR (2013). The C allele of a synonymous SNP (rs1805414, Ala284Ala) in PARP1 is a risk factor for susceptibility-breast cancer in Saudi patients. Asian Pac J Cancer Prev, 14, 3051-6.

Avery CL (2007). Genotype-by-smoking interaction and the risk of atherosclerosis and its clinical sequelae. PhD Thesis, Epidemiology Department, University of North Carolina at Chapel Hill, USA.

Azizun-Nisa, Bhurgri Y, Raza F, Kayani N (2008). Comperison of ER, PR and HER-2/neu (C erb B2) reactivity pattern with histologic grade, tumor size and lymph node status in breast cancer. Asian Pac J Cancer Prev, 9, 553-6.

Bhakat KK, Mantha AK, Mitra S (2009). Transcriptional regulatory functions of mammalian AP-endonuclease (APE1/Ref-1), an essential multifunctional protein. Antioxid Redox Signal, 11, 621-38.

Dumitrescu RG, Cotarla I (2005). Understanding breast cancer risk-where do we stand in 2005? J Cell Mol Med, 9, 208-21.

Dyrkheeva NS, Khodyreva SN,Lavrik OI (2007). Multifunctional 
human apurinic/apyrimidinic endonuclease 1: the role of additional functions. Mol Biol (Mosk), 41, 450-66.

Fishel ML and Kelley MR (2007). The DNA base excision repair protein Ape1/Ref-1 as a therapeutic and chemopreventive target. Mol. Aspects Med, 28, 375-95.

Grantham R (1974). Amino acid difference formula-help explain protein evolution. Science, 185, 862-4.

Hedayati-Moghadam MR (2008). Correlation of HER2/neu overexpression, p53 protien accumulation and steroid receptor status with tumor characteristics: an Iranian study of breast cancer patients. Iranian J Publ Health, 37, 19-28.

Hu JJ, Smith TR, Miller MS, et al (2001). Amino acid substitution variants of APE1 and XRCC1 genes associated with ionizing radiation sensitivity. Carcinogenesis, 22, 917-22.

Kang H, Dai Z, Ma X, et al (2013). A genetic variant in the promoter of APE1 gene $(-656 \mathrm{~T}>\mathrm{G})$ is associated with breast cancer risk and progression in a Chinese population. Gene, 15, 97-100.

Karahalil B, Bohr VA, Wilson DM (2012). Impact of DNA polymorphisms in key DNA base excision repair proteins on cancer risk. Hum Exp Toxicol, 31, 981-1005.

Kim KY, Han W, Noh DY, Kang D, Kwack K (2013). Impact of genetic polymorphisms in base excision repair genes on the risk of breast cancer in a Korean population, Gene, 15, 192-6.

Kumar P, Henikoff S, Ng PC (2009). Predicting the effects of coding non-synonymous variants on protein function using the SIFT algorithm. Nat Protoc, 4, 1073-81.

Li Q, Wang JM, Peng Y, et al (2013). Association of DNA base excision repair XRCC1, OGG1 and APE1 gene polymorphisms with nasopharyngeal carcinoma susceptibility in a Chinese population. Asian Pac J Cancer Prev, 14, 5145-51.

Li Z, Guan W, Li MX, et al (2011). Genetic polymorphism of DNA base-excision repair genes (APE1, OGG1 and XRCC1) and their correlation with risk of lung cancer in a Chinese population. Arch Med Res, 42, 226-34.

Lo YL, Jou YS, Hsiao CF, et al (2009). A polymorphism in the APE1 gene promoter is associated with lung cancer risk. Cancer Epidemiol Biomarkers Prev, 18, 223-9.

Lodish, Havery (2004). Molecular Cell Biology. W.H. Freeman and Company, New York, p. 113. ISBN 0-7167-4366-3.

Lu J, Zhang S, Chen D, et al (2009). Functional characterization of a promoter polymorphism in APE1/Ref-1 that contributesreduced lung cancer susceptibility. FASEB J, 23, 3459-69.

Luo H, Li Z, Qing Y, et al (2014). Single nucleotide polymorphisms of DNA base excision repair genes (APE1, OGG1 and XRCC1) associated with breast cancer risk in a Chinese population. Asian Pac J Cancer Prev, 15, 1133-40.

Mahjabeen I, Baig RM, Sabir M, Kayani MA (2013). Genetic and expressional variations of APEX1 are associated with increased risk of head and neck cancer. Mutagenesis, 28, 213-8.

Naeem M, Nasir A, Aman Z, Ahmad T, Samad A (2008). Frequency of HER2/neu receptor positivity and its association with other features of breast cancer. J Ayub Med Coll Abbottabad, 20, 23-6.

Nosheen M, Ishrat M, Malik FA, Baig RM, Kayani MA (2010). Association of GSTM1 and GSTT1 gene deletions with risk of head and neck cancer in Pakistan: a case control study. Asian Pac J Cancer Prev, 11, 881-5.

Pollard KS, Hubisz MJ, Rosenbloom KR, Siepel A (2010). Detection of non-neutral substitution rates on mammalian phylogenies. Genome Res, 20, 110-21.

Popanda O, Seibold P, Nikolov I, et al (2013). Germline variants of base excision repair genes and breast cancer: a polymorphism in DNA polymerase gamma modified gene expression and breast cancer risk. Int J Cancer, 132, 55-62.
Rampaul RS, Pinder SE, Elaston CW, Ellis IO (2001). Prognostic and predictive factors in primary breast cancer and their role in patient management; the Nottingham breast team. Eur $J$ Surg Oncol, 27, 229-38.

Retrieved May 20, 2014, from http://www.hgvs.org/mutnomen/.

Rosenberg SM, Partridge AH (2013). Premature menopause in young breast cancer: effects on quality of life and treatment interventions. J Thorac Dis, 5, 55-61.

Schultz PN, Klein MJ, Beck ML, Stava C, Sellin RV (2005). Breast cancer relationship between menopausal symptoms, physiologic health effects of cancer treatment and physical constraints on quality of life in long-term survivors. J Clin Nurs, 14, 204-11.

Schwarz JM, Rodelsperger C, Schuelke M, Seelow D (2010). Mutation taster evaluates disease-causing potential of sequence alterations. Nat Methods, 7, 575-6.

Shakeel S, Mahjabeen I, Mahmood Akhtar Kayani MA, Faryal R (2013). Association of SYK genetic variations with breast cancer pathogenesis. Asian Pac J Cancer Prev, 14, 3309-14.

Sharif MA, Mamoon N, Mushtaq S, Khadim MT, Jamal S (2010). Steroid hormone receptor association with prognostic markers in breast carcinoma in Northern Pakistan. J Coll Physicians Surg Pak, 20, 181-5.

Wang M, Chu H, Wang S, et al (2013). Genetic variant in APE1 gene promoter contributes-cervical cancer risk. Am J Obstet Gynecol, 360 1-7.

Wang M, Qin C, Zhu J, et al (2010). Genetic variants of XRCC1, APE1, and ADPRT genes and risk of bladder cancer. DNA Cell Biol, 29, 303-11.

Wong D, DeMott MS, Demple B (2003). Modulation of the 3'-->5'-exonuclease activity of human apurinic endonuclease (Ape1) by its 5' -incised Abasic DNA product. J Biol Chem, 278, 36242-9.

Zhang Y,Polly A. Newcomb, et al (2006). Genetic polymorphisms in base-excision repair pathway genes and risk of breast cancer. Cancer Epidemiol Biomarkers Prev, 15, 353-8.

Zhang Y, Wang J (2010). Anticancer clinical utility of the apurinic/apyrimidinic endonuclease/redox factor-1 (APE/ Ref-1). Chin J Cancer, 29, 333-9.

Zhou B, Shan H, Su Y, et al (2011). The association of APE1 $-656 \mathrm{~T}>\mathrm{G}$ and $1349 \mathrm{~T}>\mathrm{G}$ polymorphisms and cancer risk: a meta-analysis based on 37 case-control studies. BMC Cancer, 11, 521-9.

Zhou K, Hu D, Lu J, et al (2011). A genetic variant in the APE1/Ref-1 gene promoter -141T/G may modulate risk of glioblastoma in a Chinese Han population. BMC Cancer, 23, 104-11.

Zhou LP, Luan H, Dong XH, et al (2012). Association of functional polymorphisms of the XRCC4 gene with the risk of breast cancer: a meta-analysis. Asian Pac J Cancer Prev, 13, 3431-6. 